Faculty of Economics and Social Sciences

Department of Economics

\title{
Does a Platform Monopolist Want Competition?
}

Andras Niedermayer

06-04

December 2006

\section{DISCUSSION PAPERS}




\title{
Does a Platform Monopolist Want Competition?
}

\author{
Andras Niedermayer*
}

December 6, 2006

\begin{abstract}
We consider a software vendor first selling a monopoly platform and then an application running on this platform. He may face competition by an entrant in the applications market. The platform monopolist can benefit from competition for three reasons. First, his profits from the platform increase. Second, competition serves as a credible commitment to lower prices for applications. Third, higher expected product diversity may lead to higher demand for his application. Results carry over to non-software platforms and, partially, to upstream and downstream firms. The model also explains why Microsoft Office is priced significantly higher than Microsoft's operating system.
\end{abstract}

Keywords: Platforms, entry, complementary goods, price commitment, product diversity, Microsoft, vertical integration, two-sided markets

JEL-Classification: D41, D43, L13, L86

${ }^{*}$ Economics Department, University of Bern, Schanzeneckstrasse 1, CH-3001 Bern, Switzerland. Email: niedermayer@vwi.unibe.ch. I thank Philipp Ackermann, Simon Anderson, Werner Boente, Stefan Buehler, Alain Egli, Winand Emons, Roland Hodler, Simon Loertscher, Gerd Muehlheusser, Daniel Niedermayer, Ferenc Niedermayer, Armin Schmutzler, Dezső Szalay, and Lucy White for very helpful comments. I further thank participants of seminars at the University of Bern, SSES 2006 in Lugano, IIOC 2006 in Boston, Swiss IO Day 2006 in Bern, EARIE 2006 in Amsterdam, and YSEM 2006 in Bern for valuable discussions. Any errors are mine. 


\section{Introduction}

Platforms play an important role in many markets. A platform gives two sides (e.g. sellers and buyers) the possibility to interact (e.g. trade) with each other. The platform owner may get part of the generated surplus.

In software market: 1 platforms play a crucial role: it would be too costly to develop a new application for every possible combination of hardware, versions of operating systems, file formats, etc 2 A software platform provides a common interface between different applications and different configurations of users' systems. Hence, it enables application developers on one side and end users on the other side to interact with each other 3 We will consider applications running on a platform, i.e. pieces of software that are only usable in conjunction with the platform. An example are the spreadsheet calculation programs MS Excel and Lotus 1-2-3 for the platform MS Windows 4 Two interesting observations arise when considering this and other examples. First, the platform owner also owns several (but not all) of the applications running on its platform. Second, the platform owner makes a large part of its profits with the applications. The second observation has been well described in the two-sided markets literature, however, the first observation - especially that the platform owner owns part of the applications market - has not been treated extensively. This paper looks in detail at the specific effects arising in markets with the aforementioned ownership structure. The main result of our paper is that we can explain two seemingly contradictory facts observed in both software and non-software markets. First, a firm active in both the platform and the applications market often encourages entry to the applications market. Second, as mentioned before, such firms often get large parts of their profits from the applications market. Our model explains both facts at the same time 5

\footnotetext{
${ }^{1}$ Our main focus in this paper are software platforms, however, results apply to non-software platforms and relations of upstream and downstream firms, as well.

${ }^{2}$ For example if one wants to use a word processing application to write a letter and print it one needs besides the application at least a computer and a printer. If consumers have the choice between $C$ types of computer hardware and $P$ printers an application developer would need to write an application which can deal with all $C \times P$ combinations of computer hardware and printers. A software platform offers a common interface to all combinations and the application needs to deal with only one combination. For a survey of the economic role of software platforms in computer-based industries see Evans, Hagiu, and Schmalensee (2004).

${ }^{3}$ We will use the term "software platform" with a very broad meaning: it can mean an operating system (such as Windows or Linux), a file format (e.g. Adobe's PDF, Microsoft Word documents, OpenOffice documents), virtual machines (e.g. Sun's Java Platform, Microsoft's .NET Platform), database access interfaces (e.g. the Structured Query Language) or game consoles (e.g. Sony's Playstation 2 and Microsoft's XBox).

${ }^{4}$ More examples are given in Appendix $\mathrm{A}$

${ }^{5}$ With a simple model one can explain either of the two facts: if the platform owner has the better appli-
} 
Our model can also be seen in relation to an observed pattern described in Evans, Hagiu, and Schmalensee (2004): Firms often start as vertically integrated monopolists selling both a platform and all of the applications for the platform. At some point of their development they make the decision to open the applications market to other firms and operate the platform as a two-sided market. Our model deals with the question under which circumstances a transition from a vertically integrated firm to an open platform becomes attractive 6

More specifically, our model considers the setup of a platform monopolist who also owns an application running on his platform. An independent firm considers developing a further, horizontally differentiated application for the platform. To be able to focus on this ownership structure, this paper will abstract away from issues usually considered in the two-sided markets literature, such as charging royalties to one side and subsidizing the other side. Consumers are heterogeneous in both their preferences for the platform and the applications. They buy the platform at the first stage of the game. At the second stage they learn their preferences about the applications 7

There are three positive effects of competition for the platform monopolist in our model. First, the platform vendor makes more profits with his platform. This is a well-known effect observed when there are two markets with complementary goods. If competition increases in market 1, profits of firms active in the complementary market 2 increase. We will call this the complementarity effect 8 Second, the competitor's entry serves as a credible commitment to lower prices for applications. Without a credible price commitment mechanism consumers will fear that they will be overcharged in the second period when they buy the application. Therefore, they will not be willing to buy the platform in the first place. Competition is a remedy for this hold-up problem. This price commitment effect differs from the previous effect because here more competition in market 1 leads to higher profits in market 1 itself.

cation, he will bundle it with the platform and hence exclude other application providers. If his application is worse than the competitor's, he will drop his application, make money with his platform only, and let his competitor sell the application. Appendix $\mathrm{A}$ and Evans, Hagiu, and Schmalensee (2004) provide examples where the two seemingly contradictory facts are observed.

${ }^{6}$ One has to note that opening the platform is in many cases even more attractive for the integrated firm than described here, because contrary to our model the platform owner may charge a royalty to application developers in a two-sided market (e.g. game consoles). This is not an issue in the example we consider - PC applications - here no royalties are charged.

${ }^{7}$ Uncertainty about stage two preferences can be due to learning-by-doing or because the new versions of the applications will be released in the future.

${ }^{8}$ Economides (1997) and Parker and Van Alstyne (2000) describe this effect for software markets. This effect is not unique to software markets or platforms. E.g. if there is more competition among car vendors, profits of gasoline suppliers will go up. 
The basic idea is that competition forces the former monopolist to share the pie (i.e. the market for applications), however, the pie also becomes larger. Third, higher expectations of product diversity lead to a higher demand for the platform and thus for the applications. For this product diversity effect the same argument of getting a smaller slice of a larger pie applies as for the second effect. Interestingly, the product diversity effect can be sufficient to offset the negative effects of competition.

An implication of the results of this paper is that if the platform owner is better off with a competing application, but the potential entrant is unwilling to enter, then the platform owner may encourage competition.

Related Literature. Our model is related to the recent strain of literature on two-sided markets. Caillaud and Jullien (2003), Rochet and Tirole (2003), and Armstrong (2005) consider platform owners as intermediaries who help matching a continuum of sellers and buyers. The focus in this literature is usually on the platform and not the applications as in our model. Nocke, Peitz, and Stahl (2004) look at the impact of ownership structures on platform size and product variety. They consider the cases where either all sellers (application vendors in our terminology) or none of them own the platform. The situation of our model where a part of the applications belongs to the same firm as the platform is not considered. We differ from Hagiu (2004) by considering the effects of commitment to an application price and not a platform price. The main difference of our model to the literature is that we do not have a continuum of sellers, but either a monopolist or two duopolists. Our focus is not on the platform, but on the imperfect competition on the application side of the market. A problem similar to the one we deal with is mentioned in Nocke, Peitz, and Stahl (2004): if a further application developer enters, it is ambiguous whether profits of incumbent application developers fall or rise. Beggs (1994) looks at potential benefits of a merger for members of a platform whereas we look at the benefits of entry 9

The question considered in this paper also has similarities to the questions investigated in the network externalities literature. Economides (1997) and Parker and Van Alstyne (2000) consider a platform owner who induces more competition in the applications market to get higher profits in the platform market 10 Economides (1996) looks at a monopolist who is

\footnotetext{
${ }^{9}$ Beggs (1994) is not part of the two-sided markets literature, but the paper does deal with competition of platforms such as computer systems or shopping malls.

${ }^{10}$ The second sourcing literature provides an intertemporal version of this complementarity effect: a monop-
} 
willing to induce competition as a means of committing to higher quantities. Our model also shows the effects described by Parker and Van Alstyne and Economides (with the difference that it has price and not quantity commitment), but introduces a third effect: the product diversity effect.

The paper is structured as follows. Section 2 describes the setup of the basic model. Sections 3 and 4 treat the cases of monopoly and competition. Section 5 compares the monopolist's profits for the two cases. Section [6] shows how the three aforementioned effects of competition can be distinguished. Section [7 applies the results to the pricing of Microsoft's products. Section 8 concludes. Appendix $\mathrm{A}$ gives examples for which our model is applicable. Appendices [B] [C] and $\mathrm{E}$ discuss outcomes under alternative assumptions. Appendix [D looks at the case when the monopolist can develop the alternative application himself (or acquire the competitor).

\section{Model}

Consider a software market with two firms, A and B. Firm A produces two goods: a platform and an application 11 B considers developing an application for A's platform (see bottom of Fig. 11). B is the only firm capable of producing her application 12 B's application is usable with A's platform only.

Now let us consider the potential buyers of the platform and the applications. We assume a continuum of consumers with heterogeneous preferences over the platform $y \in[0, \infty)$ and over the applications $x \in[0,1]$ as shown at the top of Fig. 1. One can imagine $y$ as the distance of a consumer from the platform: the further one is (i.e. the greater $y$ ), the less

olist (e.g. a patent holder) induces more competition in the second period market to get higher profits in the complementary first period market. See Farrell and Gallini (1988).

${ }^{11}$ One can think of the platform as being an operating system (e.g. MS Windows) and the applications being software written for this operating system (e.g. MS Excel, Lotus 1-2-3). Further examples are mentioned in Appendix A

${ }^{12}$ This is either because of her unique expertise in programming this piece of software or because of legal issues (e.g. copyright laws, patents or non-competition clauses for her lead developers). It is actually sufficient to assume that other firms' development costs would be prohibitively high to develop the application. An alternative would be to allow for the platform owner to develop the other application as well, but to assume endogenous location of the applications and quadratic instead of linear transportation costs. Then, if there are two firms developing applications there is a commitment to product diversity (maximum product differentiation). This is in contrast to only one firm developing applications which would be less committed to providing diversified products. Appendix $\mathrm{D}$ derives results for the case that firm A produces both applications and compares them with the results of Sections 3 and 4 


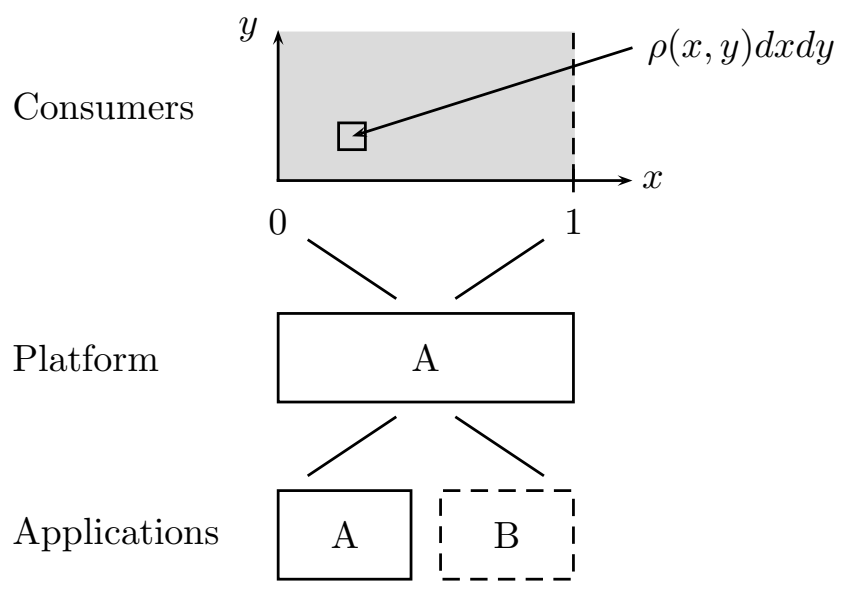

Figure 1: Applications by A and B; platform by A; distribution of consumers' preference parameters $x$ (applications) and $y$ (platform)

willing one is to buy the platform $13 x$ is the location of the consumer in a fixed location Hotelling competition between applications A and B where A is exogenously located at 0 and $\mathrm{B}$ at 1 . This means that consumers with a small $x$ are more willing to buy A and less willing to buy B than consumers with a large $x$. Consumers' utility is set to 0 for the case they do not buy the platform (and hence cannot use any of the applications either), $v_{0}=s-p-y$ if they buy the platform without any applications $14 v_{A}=v_{0}+s_{A}-p_{A}-t x$ if they buy the platform with application $\mathrm{A}$ and $v_{B}=v_{0}+s_{B}-p_{B}-t(1-x)$ if they buy it with application B. $s$ is the intrinsic value of the platform, $p$ is the price of the platform, $s_{A}$ and $s_{B}$ are the gross utilities (without "transportation costs") consumers derive from applications A and B respectively, $p_{A}$ and $p_{B}$ are the prices of the applications and $t$ represents the "transportation costs" in the choice of the application 15 We will assume that consumers learn their preferences $x$ over applications only after having bought the platform 16 Like in the standard Hotelling setup, we assume that consumers cannot or do not want to buy both applications. We further

\footnotetext{
${ }^{13}$ Or one can consider $y$ to be the outside option of a consumer as in Nocke, Peitz, and Stahl (2004).

${ }^{14}$ The possibility of buying the platform with neither application A nor application B can be justified by the idea that the platform is bundled with an application or that there is a further application $\mathrm{C}$ which is not competing with applications A and B.

${ }^{15}$ This means that the higher the "transportation costs" the less willing consumers are to buy an application which is further away from their preferred type of application.

${ }^{16}$ This can be a learning-by-doing effect: only trying different applications can show which is suitable for one's own needs. In this case $y$ represents learning costs. Alternatively one can consider applications A and B as future releases of software, one does not know one's preferences about software which has not been released yet, however, one can use the platform with current versions of applications which are outside of the model.
} 
assume a constant density of consumers $\rho(x, y)=\alpha$ for $0 \leq x \leq 1$ and $y \geq 0$ and $\rho(x, y)=0$ otherwise 17

To simplify the description of the model we will call all consumers with the same $y$ a consumer unit 18

Our model has the following timing:

- Stage 0: A already has a platform and an application, B decides whether to enter,

- Stage 1: A sets price for platform, consumers buy platform,

- Stage 2: A and B set prices for applications, consumers learn their $x$ and buy applications.

We will first consider the case where B decides not to enter, A thus having a monopoly both in the platform and the applications market, and set up and solve the model backwards. In the second case we consider the situation where B enters and solve the model backwards again. If B's revenues from entering are higher than the fixed costs she incurs from developing the application, B will be willing to enter. Then we will compare firm A's profits for the two cases.

\section{Monopoly}

We will first consider profits from application sales and consumer surplus per consumer unit at stage 219 Afterwards, at stage 1, we will look at the platform choice of consumers and thus determine the number of consumer units. Assuming subgame perfection, at stage 2 players take the outcomes of stage 1 as given and do not have to fulfill any promises or threats.

\footnotetext{
${ }^{17}$ For the application pricing part we only need the assumption of uniformity over $x$, i.e. $\rho(x, y)=\rho(y)$ for $0 \leq x \leq 1$. One could easily extend the platform pricing part with a stepwise uniform density, e.g. $\rho(y)=\alpha_{1}$ for $0 \leq y<y_{1}$ and $\rho(y)=\alpha_{2}$ for $y \geq y_{1}$.

${ }^{18} \mathrm{An}$ alternative interpretation of the model is that one consumer has a specific $y$ and stochastic preferences over the applications determined by $x$. Then $x$ is a random variable uniformly distributed between 0 and 1 and is only known to consumers at stage 2. According to this interpretation a consumer unit is equivalent to a consumer.

${ }^{19}$ According to the alternative interpretation provided in footnote 18 we calculate ex ante expected consumer surplus per consumer. Because the $x$ of a consumer is not known to the firms even at stage 2, they maximize expected profits per consumer.
} 


\subsection{Stage 2}

Consider stage 2 of the case where B does not enter. In this case A is a monopolist in the applications market as well. Let us only consider consumers who have bought the platform. They have to decide whether they want to buy application A additionally to the platform or want to use the platform alone. Consumers not buying the application derive utility $v_{0}$ from the usage of the platform. Consumers buying application A have a utility of $v_{A}$. To simplify analysis we will only consider excess utility compared to $v_{0}$ : excess utility for using the platform alone is 0 , for using application $\mathrm{A} v_{A}-v_{0}=s_{A}-p_{A}-t x$.

Now let us consider a consumer unit whose members have bought the platform 20 According to the assumption made previously consumers are uniformly distributed along the $x$-axis between 0 and 1 , therefore we get a one-sided version of the standard fixed location Hotelling setup where a monopolist sells goods to consumers with heterogeneous preferences.

We will assume that A has an incentive to sell to all consumers (i.e. full market coverage, see Fig. 2). For this, we need to assume that transportation costs are low enough (or that the gross utility derived from application A is high enough):

$$
s_{A} \geq 2 t
$$

Proposition 1. If the gross utility derived from application $A$ is high enough $\left(s_{A} \geq 2 t\right)$, the monopolist will sell to all consumers and will set the outermost consumer indifferent between buying and not buying.

For a formalization and a proof of this proposition and for a treatment of the alternative case where the monopolist does not sell to consumers far away from him see Appendix $\mathbb{B}$, The effect we intend to show is even stronger in the alternative case.

With full market coverage, the monopolist will set the outermost consumer indifferent between buying his application or using the platform without the application, i.e. for $\hat{x}=1$

$$
s_{A}-p_{A}-t \hat{x}=0
$$

where $\hat{x}$ is the location of the indifferent consumer (see Fig. 2)

\footnotetext{
${ }^{20}$ Note that $x$ is not known in the first period, therefore only perceived heterogeneity in $y$ exists for consumers when deciding whether to buy the platform. In pure strategies either all consumers with a specific $y$ buy the platform or none.
} 


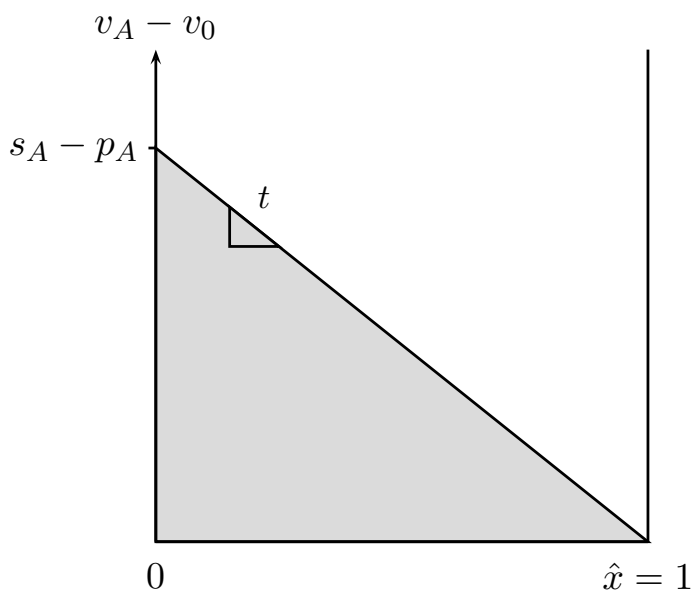

Figure 2: Monopolist A selling the application to all consumers who have bought the platform. The shaded area under the curve denotes the consumer surplus.

Thus, under the assumption of full market coverage, we get the optimal price

$$
p_{A}^{*}=s_{A}-t
$$

For equilibrium profits per consumer unit from sales of the application we get

$$
\pi_{A}^{*}=p_{A}^{*} \hat{x}=s_{A}-t
$$

under the assumption of zero marginal costs.

For the sake of clarity, profits per consumer unit at stage 2 will be denoted with a lower case $\pi$, total profits at stage 1 will be denoted with an upper case $\Pi$.

The consumer surplus per consumer unit is the integral of consumers' utilities over $x$, as denoted in the shaded area in Fig. 2

$$
\mathrm{EU}=\int_{0}^{\hat{x}}\left(s_{A}-p_{A}^{*}-t x\right) d x=\frac{t}{2}
$$

using $\hat{x}=1$ and (3.2).

We denote consumer surplus with EU because it is the utility that consumers expect to derive from the purchase of the application when they form expectations at stage 1.

Having calculated the outcome of stage 2, we can proceed to stage 1, where consumers buy the platform. 


\subsection{Stage 1}

At stage 1 consumers decide whether to buy the platform. As they do not know their preferences for the application (i.e. their $x$ ) they form expectations over $x$. Their expected utility for buying the platform is $s-p-y+\mathrm{EU}$. There is an indifferent consumer unit $\hat{y}$ for whom

$$
s-p-\hat{y}+\mathrm{EU}=0
$$

as denoted in Fig. 3,

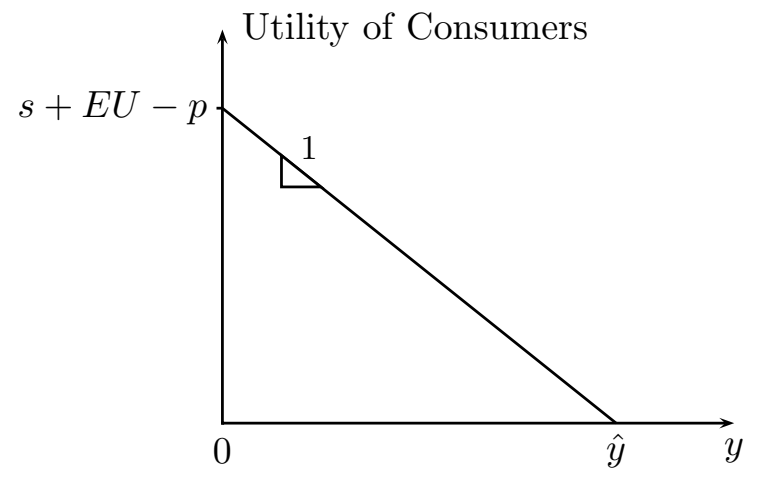

Figure 3: Platform Choice

One can get the number of consumer units (i.e. all consumers with the same $y$ ) who are willing to buy the platform by integrating the density function from 0 to $\hat{y}$ :

$$
N=\int_{0}^{\hat{y}} \int_{0}^{1} \rho(x, y) d x d y=\alpha \hat{y}=\alpha(s+\mathrm{EU}-p) .
$$

Firm A makes profits from selling its platform $(p N)$ and its application at stage $2\left(\pi_{A}^{*} N\right)$. The overall profit of firm A is thus

$$
\Pi=p N+\pi_{A}^{*} N
$$

The profit maximizing price $p^{*}$ for the platform is

$$
p^{*}=\arg \max _{p} \Pi=\frac{1}{2}\left(s+\mathrm{EU}-\pi_{A}^{*}\right)=\frac{1}{2}\left(s+\frac{3}{2} t-s_{A}\right)
$$

after solving for the first order condition and substituting $\mathrm{EU}$ and $\pi_{A}^{*}$.

$p^{*}$ is nonnegative if

$$
s+\mathrm{EU} \geq \pi_{A}^{*} \quad \Leftrightarrow \quad s \geq s_{A}-\frac{3}{2} t
$$


We assume that either $s$ is sufficiently large so that condition (3.9) is satisfied or that firm A has the possibility to set a negative $p^{*}$ (i.e. subsidize its platform) 21

For the number of consumer units buying the platform in equilibrium we get

$$
N^{*}=\frac{\alpha}{2}\left(s+\mathrm{EU}+\pi_{A}^{*}\right)=\frac{\alpha}{2}\left(s+s_{A}-t\right) .
$$

Because both EU and $\pi_{A}^{*}$ are positive $N^{*}$ is strictly positive for all nonnegative values of $s$, therefore we do not have to make further assumptions to ensure that $N^{*} \geq 0$.

Equilibrium total profits of firm A are

$$
\Pi^{*}=\frac{\alpha}{4}\left(s+\mathrm{EU}+\pi_{A}^{*}\right)^{2}
$$

or

$$
\Pi^{*}=\frac{\alpha}{4}\left[s+s_{A}-\frac{t}{2}\right]^{2} .
$$

\subsection{Stage 0}

We assume B's profits to be 0 for the case that she does not enter the market.

\section{Competition}

Now we can look at the case when B enters the market. We solve by backward induction first stage 2 and then stage 1.

\subsection{Stage 2}

Consider stage 2 of the case where B enters. Again, let us only consider consumers who have bought the platform. They have to decide whether they want to buy application A or B additionally to the platform or do not want to buy any of the applications. Consumers not buying any of the applications derive utility $v_{0}$ from the usage of the platform alone. Consumers buying application A have a utility of $v_{A}$, those buying $\mathrm{B}$ a utility of $v_{B}$. Excess utility for using the platform alone is 0 , for using application $\mathrm{A} v_{A}-v_{0}=s_{A}-p_{A}-t x$, for $\mathrm{B} v_{B}-v_{0}=s_{B}-p_{B}-t(1-x)$.

Now let us consider a consumer unit whose members have bought the platform. Because of the uniform distribution of consumers' preferences along the $x$-axis we get a standard fixed

\footnotetext{
${ }^{21}$ E.g. by offering free support for the platform or by offering an application $\mathrm{C}$ additionally to the platform for free, where $\mathrm{C}$ is not substitutable with applications $\mathrm{A}$ and $\mathrm{B}$.
} 
location Hotelling setup with firm A located at $x=0$ and firm B at $x=1$. The only difference to the standard model is that $s_{A}$ is not necessarily equal to $s_{B}$.

Here we will assume an equilibrium as depicted in Fig. 4. To exclude special cases we make some restrictions on the ranges of $s_{A}, s_{B}$ and $t$ :

$$
\begin{array}{r}
s_{A}+s_{B}>3 t \\
-3 t<s_{A}-s_{B}<3 t .
\end{array}
$$

We assume that the whole market is covered (there are no consumers who do not buy any of the applications) and that the consumer who is indifferent between $\mathrm{A}$ and $\mathrm{B}$ has a strictly positive excess utility (Eq. (4.1)). We further assume that both firms can sell strictly positive quantities of their application (i.e. neither firm's application is so much better than the other's that it could capture the whole market, Eq. (4.2)). See Appendix C] for a derivation of these restrictions and for a treatment of the cases where these assumptions are not satisfied. As noted in subsection 3.1 comparing these alternative cases with the cases mentioned in subsection 3.1 (full and partial market coverage) gives us even stronger results.

Under the aforementioned conditions all consumers buy an application (see Fig. 4). The indifferent consumer $\tilde{x}$ derives the same excess utility from applications $\mathrm{A}$ and B: $s_{A}-p_{A}-t \tilde{x}=$ $s_{B}-p_{B}-t(1-\tilde{x})$. Consumers to the left of $\tilde{x}$ buy A, those to the right of $\tilde{x}$ buy B.

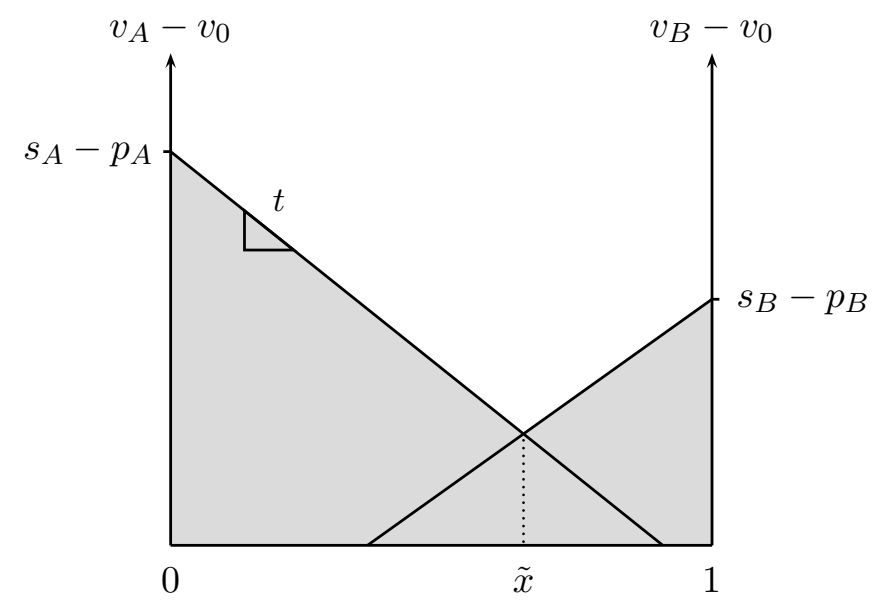

Figure 4: Application Pricing. The shaded area denotes consumer surplus. 
Demand per consumer unit for application $\mathrm{A}$ is

$$
\tilde{x}=\frac{1}{2}+\frac{1}{2 t}\left(s_{A}-s_{B}+p_{B}-p_{A}\right)
$$

and for application $\mathrm{B}$ it is $1-\tilde{x}$.

Profits per consumer unit from the sales of the applications are $\pi_{A}=p_{A} \tilde{x}$ and $\pi_{B}=$ $p_{B}(1-\tilde{x})$.

Profit maximizing Nash equilibrium prices are

$$
\begin{aligned}
& p_{A}^{*}=\arg \max _{p_{A}} \pi_{A}\left(p_{A}, p_{B}^{*}\right)=t+\frac{\Delta}{3}, \\
& p_{B}^{*}=\arg \max _{p_{B}} \pi_{B}\left(p_{A}^{*}, p_{B}\right)=t-\frac{\Delta}{3} .
\end{aligned}
$$

with $\Delta \equiv s_{A}-s_{B}$. Because profit functions are concave it suffices to solve the first order conditions to get these prices. The indifferent consumer is hence at location

$$
\tilde{x}^{*}=\frac{1}{2}+\frac{\Delta}{6 t}
$$

and equilibrium profits are 22

$$
\begin{aligned}
& \pi_{A}^{*}=\left(t+\frac{\Delta}{3}\right)\left(\frac{1}{2}+\frac{\Delta}{6 t}\right) \\
& \pi_{B}^{*}=\left(t-\frac{\Delta}{3}\right)\left(\frac{1}{2}-\frac{\Delta}{6 t}\right)
\end{aligned}
$$

The consumer surplus per consumer unit is the integral of consumers' utilities over $x$, as denoted in the shaded area in Fig. 4

$$
\mathrm{EU}=\int_{0}^{\tilde{x}^{*}}\left(s_{A}-p_{A}^{*}-t x\right) d x+\int_{\tilde{x}^{*}}^{1}\left(s_{B}-p_{B}^{*}-t(1-x)\right) d x,
$$

substituting $p_{A}^{*}, p_{B}^{*}$ and $\tilde{x}^{*}$ we get

$$
\mathrm{EU}=\frac{\Delta^{2}}{36 t}+\frac{s_{A}}{2}+\frac{s_{B}}{2}-\frac{5}{4} t
$$

Again, we can use stage 2 results for stage 1.

\footnotetext{
${ }^{22}$ These results are consistent with the standard Hotelling model where $s_{A}=s_{B}$. In the standard Hotelling model equilibrium prices are $p_{A}^{*}=p_{B}^{*}=t$ and equilibrium profits are $\pi_{A}^{*}=\pi_{B}^{*}=t / 2$. Substituting $\Delta=0$ into (4.3), 4.4, 4.5) and (4.6) gives us the same results.
} 


\subsection{Stage 1}

As in the case where B does not enter, consumers' valuation for the platform depends on the intrinsic value of the platform plus the expected value of the applications at stage 2 . The only difference is that here consumers anticipate that they will have the choice between applications $\mathrm{A}$ and $\mathrm{B}$ at stage 2 and adjust their expectations accordingly. Their expected utility for buying the platform is $s-p-y+$ EU. Consumers with $y \in[0, \tilde{y}]$ buy the platform where the location of the indifferent consumer is given by

$$
\tilde{y}=s-p-\mathrm{EU}
$$

The number of consumer units is

$$
N=\int_{0}^{\tilde{y}} \int_{0}^{1} \rho(x, y) d x d y=\alpha \tilde{y}=\alpha(s+\mathrm{EU}-p) .
$$

Firm A's overall profits are still $\Pi=p N+\pi_{A}^{*} N$ but with a different $\pi_{A}^{*}$ this time. By analogy to subsection 3.2 we get

$$
\begin{aligned}
p^{*} & =\frac{1}{2}\left(s+\mathrm{EU}-\pi_{A}^{*}\right), \\
\Pi^{*} & =\frac{\alpha}{4}\left(s+\mathrm{EU}+\pi_{A}^{*}\right)^{2}
\end{aligned}
$$

for equilibrium platform price and total profits.

Substituting the values of EU and $\pi_{A}^{*}$ for the case where B enters the market, we get

$$
p^{*}=\frac{1}{2}\left(s-\frac{\Delta^{2}}{36 t}+\frac{1}{6} s_{A}+\frac{5}{6} s_{B}-\frac{7}{4} t\right)
$$

and

$$
\Pi^{*}=\frac{\alpha}{4}\left[s+\frac{\Delta^{2}}{12 t}+\frac{5}{6} s_{A}+\frac{1}{6} s_{B}-\frac{3}{4} t\right]^{2} .
$$

As in Section 3.2 we assume that A can either subsidize the platform or that the parameters satisfy the condition

$$
s \geq \frac{\Delta^{2}}{36 t}+\frac{1}{6} s_{A}+\frac{5}{6} s_{B}-\frac{7}{4} t
$$

and thus we do not have to care about the constraint $p^{*} \geq 0$.

Again, as in Section $3.2 N^{*}$ is positive for nonnegative values of $s$. 


\subsection{Stage 0}

Before entering the market, B anticipates revenues per consumer unit $\pi_{B}^{*}$ for stage 2 and the number of consumer units $N^{*}$ buying the platform for stage 1. If B's total expected revenues $\pi_{B}^{*} N^{*}$ exceed her development costs $f_{B}$, B will enter the market. B's market entry condition is hence

$$
\pi_{B}^{*} N^{*}-f_{B} \geq 0
$$

\section{Comparison of Profits}

Having calculated A's profits for monopoly and competition we can look at the central question of this article: Does a Monopolist Want Competition?

We will denote A's profits in the case of being a monopolist as given in Eq. (3.11) with $\Pi^{* M}$, in the case of facing competition as given in Eq. (4.12) with $\Pi^{* C}$.

The expressions in brackets in (3.11) and (4.12) are nonnegative 23 therefore one can compare them directly. This means that $\Pi^{* C} \stackrel{?}{>} \Pi^{* M}$ is equivalent to

$$
s+\frac{\Delta^{2}}{12 t}+\frac{5}{6} s_{A}+\frac{1}{6} s_{B}-\frac{3}{4} t \stackrel{?}{>} s+s_{A}-\frac{t}{2} .
$$

Regrouping yields

$$
\Delta^{2}-2 t \Delta-3 t^{2} \stackrel{?}{>} 0
$$

The condition is fulfilled if $\Delta$ is not between the two roots of the polynomial in $\Delta$, the roots being $\Delta_{1}=-t$ and $\Delta_{2}=3 t$. Combining this result with the condition in Eq. (4.2) we get

$$
\begin{aligned}
& \Pi^{* C}>\Pi^{* M} \text { for }-3 t<\Delta<-t \text { and } \\
& \Pi^{* C}<\Pi^{* M} \text { for }-t<\Delta<3 t .
\end{aligned}
$$

Thus if B's product is better than A's $\left(s_{A}-s_{B}<-t\right)$, but not good enough to take over the whole market $\left(s_{A}-s_{B}>-3 t\right) \mathrm{A}$ is better off if $\mathrm{B}$ enters the market. Area I in Fig. [5] shows the combinations of $s_{A}, s_{B}$ and $t$ for which competition is desirable for the monopolist.

Appendix D compares the monopoly and the competition case with the situation where firm A offers both applications.

\footnotetext{
${ }^{23}$ This can be seen by looking at the intermediary steps for the calculation of total first stage profits (3.10) and (4.10): We assume that the platform has a nonnegative intrinsic value to consumers $(s \geq 0)$. The consumer surplus per consumer unit EU and per consumer unit profits from selling application A $\pi_{A}^{*}$ are also both nonnegative. Thus their sum (the expression in the brackets) has to be nonnegative as well.
} 


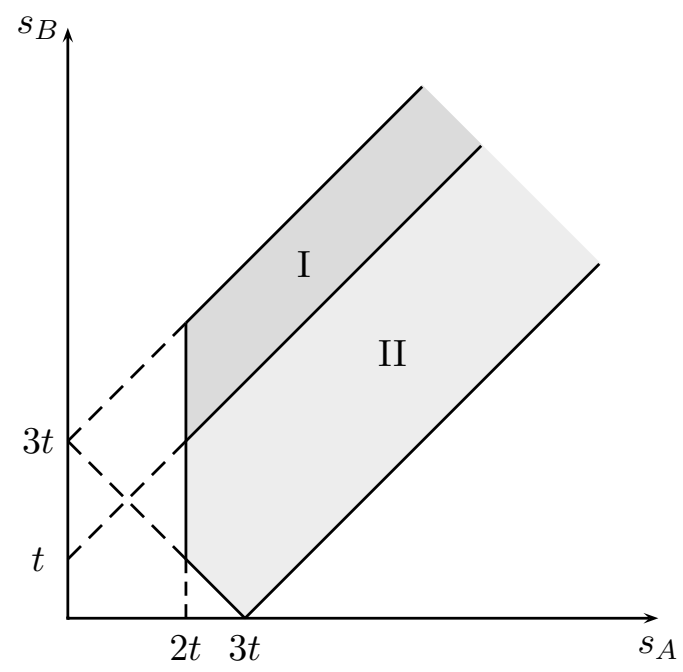

Figure 5: Areas I and II are permissible under the assumptions made $\left(s_{A} \geq 2 t, s_{A}+s_{B}>3 t\right.$ and $-3 t<s_{A}-s_{B}<3 t$ ). In area I the platform monopolist has higher profits in the competition case. ( $s_{A}$ : quality of application $\mathrm{A}, s_{B}$ : quality of application $\mathrm{B}, t$ : "transportation costs")

\section{Modifications}

\subsection{Modification: Zero Price Platform}

We have seen that firm A can be better off if firm B enters the market. But one could argue that it is not competition per se which is desirable for the monopolist, but competition in a market complementary to his platform. He still has a monopoly on the platform and can always make money there. In an extreme case when he cannot sell his application at all, we have the case of two complementary goods (the platform of $\mathrm{A} /$ the application of $\mathrm{B}$ ). It has already been shown (Economides (1997) and Parker and Van Alstyne (2000)) that a firm is willing to induce more competition in a complementary market.

This article differs from existing literature by showing that firm A can be better off after a market entry of $\mathrm{B}$ even if he gives away his platform for free and thus has to make its profits with his application only.

One can consider the zero price of the platform to be exogenously given 24 or the corner solution of a maximization problem 25 In this alternative setup the results from stage 2 shown

\footnotetext{
${ }^{24}$ For example the platform is an open-source operating system or an open standard.

${ }^{25}$ The corner solution $p^{*}=0$ comes up if the platform price $p^{*}$ cannot be negative and the non-negativity conditions (3.9) and (4.13) are not satisfied.
} 
in the previous sections still hold. However, stage 1 changes.

The price of the platform is $\bar{p}=0$. There is no optimization problem for firms to be solved here 26 Consumers form expectations about consumer surplus at stage 2 and decide whether to use the platform. Note that even with zero prices not all consumers are willing to use the platform 27

We get for the marginal consumer $\tilde{y}=s+\mathrm{EU}$ and for the number of consumer units $N=\alpha(s+\mathrm{EU})$. Profits for firm A are thus

$$
\Pi^{*}=\alpha \pi_{A}^{*}(s+\mathrm{EU}) .
$$

Now we can substitute the results from stage 2 for the different cases and compare total profits of firm 1.

For the case where firm B enters and there is an inner equilibrium at stage 2 substituting $\pi_{A}^{*}$ and EU from (4.5) and (4.8) gives

$$
\Pi^{* C}=\alpha\left(\frac{\Delta^{2}}{18 t}+\frac{\Delta}{3}+\frac{t}{2}\right)\left(s+\frac{\Delta^{2}}{36 t}+\frac{s_{A}}{2}+\frac{s_{B}}{2}-\frac{5}{4} t\right) .
$$

For the case where B does not enter and A covers the whole market at stage 2 we get

$$
\Pi^{* M}=\alpha\left(s_{A}-t\right)\left(s+\frac{t}{2}\right)
$$

using (3.3) and (3.4).

Because a general comparison of the two profits would be intractable, we compute $\Pi^{* C}$ $\Pi^{* M}$ for specific parameter values.

Note that $\alpha$ does not change the roots of the polynomial $\Pi^{* C}-\Pi^{* M}$, it merely scales the profits. Note further that scaling up all other parameters $\left(s, s_{A}, s_{B}, t\right)$ by a constant factor would not change the sign of $\Pi^{* C}-\Pi^{* M}$. Therefore, we do not need to look at all parameter combinations, it is sufficient to look at combinations of $\left(s / t, s_{A} / t, s_{B} / t\right)$.

The results of the numerical calculations are shown in Fig. [6] It can be seen that there are parameter ranges (the dark gray area) for which competition is attractive for the monopolist.

\footnotetext{
${ }^{26}$ Or $\bar{p}=p^{*}=0$ is the corner solution of the optimization problem.

${ }^{27}$ This may sound counterintuitive at first sight. However we often observe it in reality: e.g. not everyone uses the open-source operating system Linux or the free browser Mozilla Firefox. Many possible explanations have been named for this phenomenon: there are costs arising from the effort of installation, retraining for the usage of the new software, migration of legacy systems, paying external staff for the maintenance of the system, etc.
} 


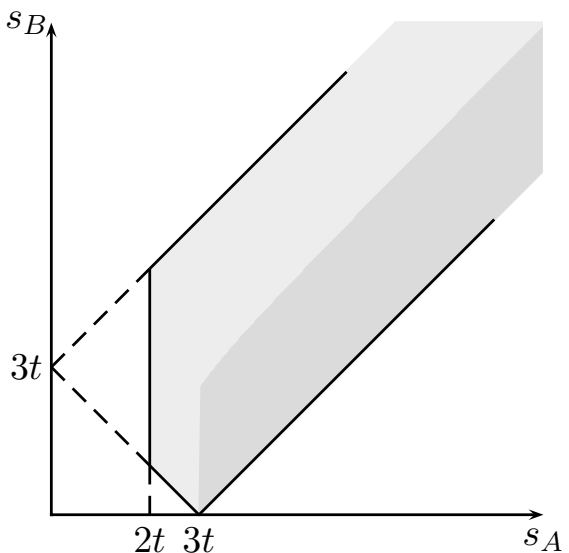

(a) $s=0$

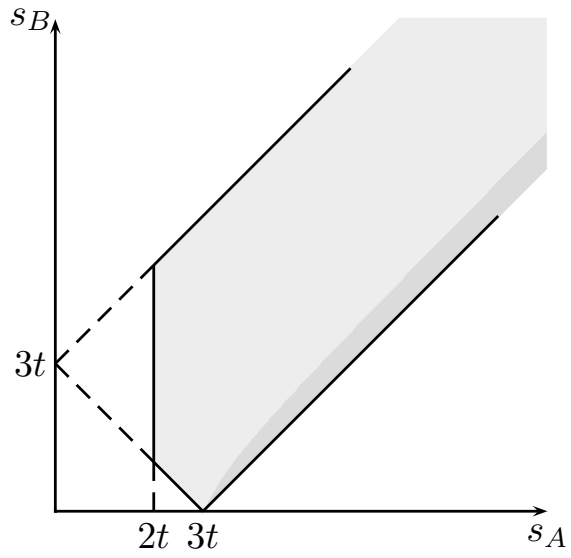

(c) $s=t$

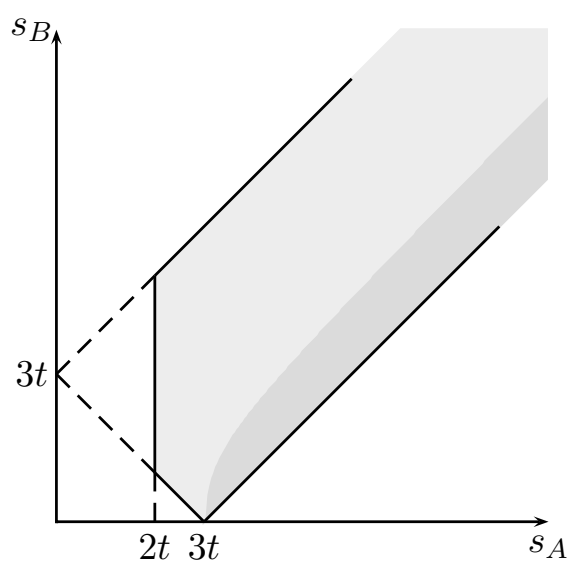

(b) $s=t / 2$

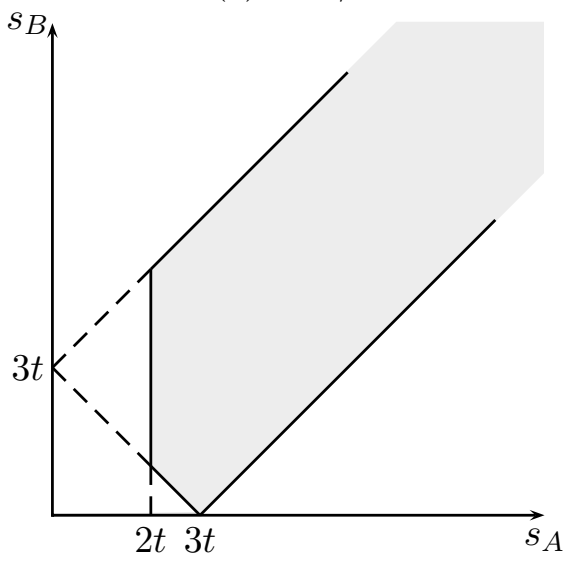

(d) $s=2 t$

Figure 6: Attractiveness of competition for the monopolist with different parameter values. The monopolist wants competition in the dark gray area; in the light gray area, he prefers monopoly.

\subsection{Modification: Zero Price Platform and Possibility of Price Commit- ment}

We have shown that competition may be attractive for the monopolist even if he has to make profits in the applications market alone. Now there are only two effects of competition left: price commitment and product diversity. In order to separate the product diversity effect we will exclude the price commitment effect of competition by assuming that the monopolist has a means to commit to a price for his application 28

We find analytical solutions for the modified model. However, as these are solutions of higher degree polynomials and hence, neither tractable nor illustrative, we substitute different

\footnotetext{
${ }^{28}$ Price commitment can be done as a price preannouncement or by selling an application already today and promising free future updates.
} 
numerical parameter values into the equations and show results for these values. (Appendix E presents a version of the model with a different distribution of consumers for which we derive purely analytical solutions. These solutions are in line with the results shown in this section.)

\subsubsection{Monopoly}

For the monopoly situation we look at two cases: full and partial coverage. In the full coverage case even the outermost consumer will buy the application at stage $2\left(p_{A} \leq s_{A}-t\right)$. Because the monopolist sets $p_{A}$ already at stage 1 , he may set a lower price than the price which sets the outermost consumer indifferent, so that more consumers are willing to buy the platform at stage 1 . Monopoly profits are $\pi_{A}=p_{A}$ per consumer unit, consumers' expected utility for stage 2 is again the integral over $x$, and overall profits for full coverage are $\Pi=\pi_{A} N=$ $p_{A} \alpha\left(s+s_{A}-p_{A}-t / 2\right)$. The profit maximizing price is $p_{A}^{\mathrm{full}}=\arg \max _{p_{A}} \Pi=s+s_{A} / 2-t / 4$ which satisfies the condition for full coverage $\left(p_{A} \leq s_{A}-t\right)$ if $s \leq s_{A} / 2-t / 4$. Substituting $p_{A}^{\text {full }}$ into $\pi_{A}$ gives us the maximal profits in the case of full coverage $\Pi^{\text {full }}$.

In the partial coverage case the monopolist does not sell to all consumers at stage 2. Profits per consumer unit are $\pi_{A}=p_{A} \hat{x}=p_{A}\left(s_{A}-p_{A}\right) / t$ with $\hat{x}$ being the indifferent consumer. Expected utility is the integral between 0 and $\hat{x}$. Profits are

$$
\Pi=\pi_{A} N=\frac{\alpha}{t^{2}} p_{A}\left(s_{A}-p_{A}\right)\left[s t+p_{A}\left(s_{A}-p_{A}\right)^{2}\left(1-\frac{p_{A}}{2}\right)\right]
$$

where $N=\alpha(s+\mathrm{EU})$. The first order condition $\left(\partial\left(\pi_{A} N\right) / \partial p_{A}=0\right)$ of the profit maximization problem is a fifth degree polynomial in $p_{A}$ and gives us five solution candidates. We check for different parameter values whether the solution candidates satisfy the following conditions: price is a nonnegative real number, second order condition, there is an indifferent consumer $(0 \leq \hat{x} \leq 1)$. For all parameter ranges considered this procedure gives us a unique solution. Substituting the optimal price into the profit function gives us the partial coverage profit $\Pi^{\text {partial }}$.

The monopolist chooses full or partial coverage depending on where profits are higher.

\subsubsection{Competition}

Stage 2 of the competition case is the same as in subsection 4.1 with the difference that only the choice of consumers has to be considered, because the firms have already committed to a 
price at stage 1 . At stage 1 firms set prices $p_{A}$ and $p_{B}$ taking into account that they influence both platform choice at stage 1 and application choice at stage 2 . The Nash equilibrium is thus

$$
\begin{aligned}
& p_{A}^{*}=\arg \max _{p_{A}} \pi_{A}\left(p_{A}, p_{B}^{*}\right) N\left(p_{A}, p_{B}^{*}\right), \\
& p_{B}^{*}=\arg \max _{p_{B}} \pi_{B}\left(p_{A}^{*}, p_{B}\right) N\left(p_{A}^{*}, p_{B}\right) .
\end{aligned}
$$

We find the Nash equilibria by solving the first order conditions. Then we check for different parameter values whether the obtained solutions candidates $\left(p_{A}^{*}, p_{B}^{*}\right)$ fulfill the following conditions: prices are nonnegative real numbers, there is an indifferent consumer $\left(0 \leq \tilde{x}\left(p_{A}^{*}, p_{B}^{*}\right) \leq\right.$ 1 ), the indifferent consumer has a positive excess utility $\left(v_{A}\left(\tilde{x}\left(p_{A}^{*}, p_{B}^{*}\right)\right)-v_{0}>0\right)$, second order conditions for A and B. For all parameter ranges considered there was no multiplicity of equilibria. However, there were parameters for which no inner equilibrium (i.e. both firms coexist and all consumers with a platform buy an application) was found. In these areas either one of the two firms dominates the market or there are local monopolies. We only consider the inner equilibrium cases and substitute equilibrium prices into A's profits which gives us $\Pi^{\text {comp }}$.

\subsubsection{Comparison}

In the cases where an inner equilibrium exists the monopolist is better off with competition if

$$
\Pi^{\text {comp }}>\max \left\{\Pi^{\text {full }}, \Pi^{\text {partial }}\right\} .
$$

We can show numerically that there are ranges of parameters where (6.3) is satisfied. These parameter ranges are shown in dark gray in Fig. 7

\section{Applying the Results: Pricing of MS Windows vs. MS Of- fice}

An often asked question during the anti-trust case against Microsoft was why Microsoft Windows is much cheaper than Microsoft Office, even though Microsoft has a monopoly in the operating systems market. As Economides and Viard (2004) note there have been difficulties answering this question. Our model gives a possible answer to this question.

We want to explain why the price of MS Windows is lower than the price of MS Office, i.e. why $p^{*}<p_{A}^{*}$ in our model. 


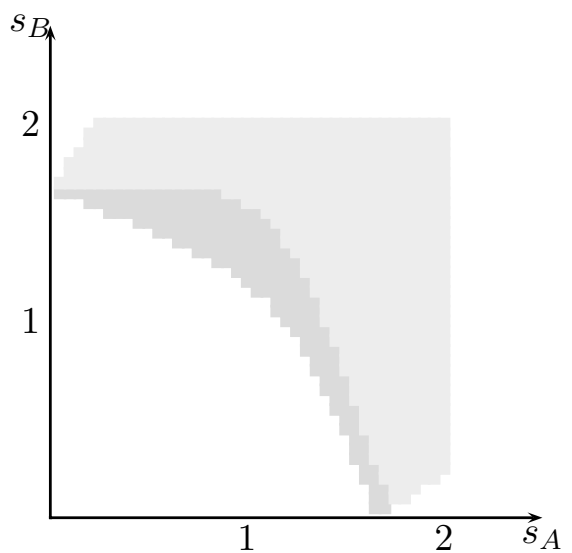

(a) $s=1 / 2$

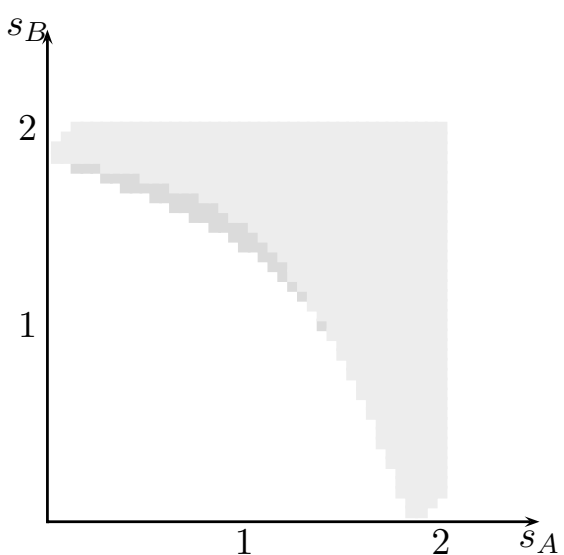

(b) $s=1$

Figure 7: Free platform and price commitment: in the dark gray area competition is attractive for the monopolist, in the light gray area it is not. Further parameters: $t=1, \alpha=1$. Numerical calculations have been done for $s_{A}, s_{B} \in[0,2]$. Note that in the empty area in the lower left corner there is no inner equilibrium.

We will first consider the monopoly and then the competition case.

Monopoly. Substituting the results obtained in Section 3 (Eqs. (3.2) and (3.8)) into $p^{*}<$ $p_{A}^{*}$ yields after regrouping $s+5 t / 2<2 s_{A}$. This means that the monopolist will charge more for the application than the platform if $s_{A}$ is high, and $s$ and $t$ are low 29

Competition. One can do the same comparison for the competition case. Substituting the results for competition from Section 4 (Eqs. (4.3) and (4.11)) into $p^{*}<p_{A}^{*}$ and regrouping gives

$$
s<\frac{15}{4} t+\frac{\Delta^{2}}{36 t}+\frac{s_{A}}{6}-\frac{s_{B}}{2} .
$$

For the allowed ranges of $s_{A}, s_{B}$ and $t$ the right-hand side of (7.1) is increasing in $s_{A}$, decreasing in $s_{B}$ and increasing in $t$.

Hence, we get the results that Microsoft is willing to price Office higher than Windows if 1. the intrinsic value $s$ of Windows is sufficiently low, 2. the substitutability of Office and competing applications is sufficiently low (i.e. $t$ is sufficiently large) 30 . the gross utility

\footnotetext{
${ }^{29} s$ may be low compared to $s_{A}$ because setup costs for the platform are higher than for the application. Lower "transportation costs" $t$ mean that consumers are less heterogeneous with respect to their preferences over applications and it is thus easier for A to charge close consumers a higher price for the application without losing the consumers who are further away.

${ }^{30}$ It is interesting to note that in the double monopoly case higher "transportation costs" $t$ lead to a lower relative price for the application; whereas if there is competition in the applications market a higher $t$ leads
} 
derived from Office $s_{A}$ is sufficiently high and 4 . the gross utility derived from competing products $s_{B}$ is sufficiently low.

Interpretation. The result that Microsoft should charge more for Office than for Windows if the quality of Office $s_{A}$ is large compared to the quality of Windows $s$ sounds trivial at first sight. However, it is not. If Windows and Office were merely complementary products Microsoft should charge more for the operating system than for the application irrespective of the relative qualities of the two products 31 The explanation of this model is that Microsoft charges a low price for Windows because it wants to convince consumers who are unsure about the quality of and their preferences for future applications to use Windows. Consumers buying new versions of Office already know their preferences and are willing to pay more.

\section{Conclusions}

If a potential application of an innovative competitor is better than his own application (but not too much better), a platform owning monopolist is better off if the competitor enters in our model. He will lose market share to the competitor, but the growth of the applications market will offset this effect and lead to higher overall profits. This may be an explanation why Microsoft encourages third party developers to develop software for Windows even if this software competes with its own applications 32

We have furthermore shown that for certain parameter combinations the platform owner can be better off after an entry of a competitor in the applications market even if he can only earn profits in the applications market itself (e.g. because the platform is an open file standard

to a higher relative price of the application. This is due to the different effects of $t$ in the two cases. For an application monopolist $t$ means a higher heterogeneity of consumers. Therefore, it is more difficult to demand a higher price from consumers with a high willingness to pay without losing those with a low willingness to pay. In contrast to this, for a firm facing competition in the applications market a high $t$ means less fierce competition.

${ }^{31}$ If Microsoft were a monopolist both in the operating system and applications market, it would not make a difference whether Microsoft charged for the operating system or the application, no matter what the qualities are. Consumers would buy the bundle anyway and only consider the sum of the two prices. Currently, however, Microsoft faces competition in the applications market and is a quasi-monopolist in the operating system market. Therefore, were Windows and Office merely complementary products, Microsoft would charge less for Office because this product faces competition, independently from the relative qualities of Windows and Office.

${ }^{32}$ One could argue that Microsoft considers its applications a "loss-leader" and prefers making money with the operating system. However, this is inconsistent with the observation that the price of MS Office ( $\$ 400$ for MS Office Standard Edition 2003 at amazon.com on July 3, 2006) is much higher than the price of MS Windows (\$88 at amazon.com) and the market share of the Office suite and the operating system are approximately equal. 
or an open source operating system). This is a possible explanation of why Adobe opened its PDF file format to competitor 33 and why commercial firms like Oracle and IBM have invested significant resources in the open source operating system Linux instead of developing an own proprietary operating system 34

We have further shown that three effects make competition attractive for the monopolist: the complementarity, the price commitment, and the product diversity effect. Interestingly, the product diversity effect alone can be strong enough to offset the negative effects of competition.

If competition is disadvantageous for the monopolist, he is willing to deter competition as long as deterrence costs are lower than the increase in profits. Deterrence can be achieved by filing broad patents, suing firms producing applications for one's platform 35 not disclosing or often changing APIs, or integrating applications with the platform. If competition is advantageous for the monopolist, but other firms are not willing to enter the applications market, the monopolist is willing to encourage competition, as long as, again, costs of encouragement are lower than the increase in profits. Encouragement can be done by "low cost licensing, ... shifting standards development to third parties, ... promising timely information to rivals" (Besen and Farrell 1994), committing not to change the APIs 36 providing cheap developer tools, and funding organizations to help developers 37

Finally, we have given a possible explanation for the observation that MS Office costs significantly more than MS Windows: Microsoft wants to convince consumers unsure about their preferences of future releases of applications to make the effort to learn to use (a new version of) MS Windows.

\section{Appendix}

\section{A Examples of Monopolists Inducing Competition}

Examples of platform owning companies which also sell an application running on their platform are provided in Table 2] Note that these firms have encouraged competition (or at least not prevented it) in their applications market in one form or the other and that they make a significant part (or

\footnotetext{
${ }^{33}$ If users want to create PDF files, they have the choice between Adobe Acrobat Standard and a large number of commercial (e.g. PDF Writer) and free (e.g. PDF Creator) software. Adobe lost market shares in the PDF creation application market to competitors, but the market grew sufficiently to offset this effect.

${ }^{34}$ IBM did of course take the effort to develop proprietary operating systems for Intel based PCs (IBM DOS and OS/2) but without much success.

${ }^{35} \mathrm{As}$ in the case of Atari suing Activision which developed games for its Atari 2600 game platform.

${ }^{36}$ Sun Microsystems e.g. engaged PriceWaterhouseCoopers to monitor its standards setting process for its Java Platform (Varian and Shapiro 1998, Chapter 8).

${ }^{37}$ E.g. Microsoft's Developer Relations Group (Evans, Hagiu, and Schmalensee 2004).
} 
even most) of their profits with their application(s) and not only with their platform. Intel as an example in Table 2 is taken from Besen and Farrell (1994). The authors also give examples of how a monopolist may encourage usage of its standard (or competition on its platform): "Concessions [to encourage adoption of the standard] include ... actions that make it more attractive for the other firm to use [the monopolist's technology]: low-cost licensing, hybrid standards, commitment to joint future development, shifting standards development to third parties, and promising timely information to rivals." Microsoft Windows and the Nintendo Entertainment System are described among other examples in detail in Evans, Hagiu, and Schmalensee (2004). Evans, Hagiu, and Schmalensee write that "Microsoft ... realized that ... it made sense to make it as attractive as possible to write software for their platform." They further write that "Nintendo [was the first console maker who] actively pursued licensing agreements with game publishers" and that Nintendo relied "on revenue from games produced in-house along with royalties from games sold by independent developers" and did not make profits with the console itself.

Adobe's PDF file format is an example as well, with the file format as a platform and software for creating files as applications. Adobe first intended the PDF file format to be a proprietary file format. But at the beginning of the 80ies they decided to open the file format to competitors. This move helped PDF to become one of the leading formats for electronic documents. This example fits our modification of a zero price platform well: Adobe does not charge royalties for the file format, however, they make money with software for the creation of PDF files 38

A further example where the model can be applied are research areas. One can consider a strain of research literature as a platform, articles in this strain as applications and readers of articles as consumers. Getting acquainted with a research area incurs investment costs and readers do not know ex ante whether the articles are worth the effort. Therefore, if there are more articles in a certain area, they are more willing to make this investment. Hence, more articles in a research area have two opposing effects on people already working in it: there are more readers of this strain of literature, but there is tougher competition for readers, as well. Either of the two effects might be stronger. The same argument applies for the choice of a language of publication as for the choice of a research area.

An example loosely related to our model which also shows similar effects (a firm wanting competitors to enter the market) are chain stores with a franchising system, e.g. McDonald's, as described in Loertscher and Schneider (2005). Consider consumers who move to another area with a certain probability and who face switching costs if they go to a different chain store in the future. Such consumers are more willing to buy a franchisee's products if there are more other franchisees of the same franchisor elsewhere.

An example of upstream/downstream firms for which this model can be applied as well is the case of AMAG Automobil- und Motoren AG. AMAG is the exclusive importer of Porsche in Switzerland and also has several branches selling Porsches directly to customers. However, they also sell Porsches to independent garages.

\section{B Alternative Cases of Monopoly}

If $\mathrm{B}$ does not enter, $\mathrm{A}$ is a monopolist at stage 2. Here two possibilities exist: if $s_{A}$ is sufficiently large $\left(s_{A} \geq 2 t\right)$ A will serve all consumers (full market coverage, see Fig. 8(a)], otherwise $\left(s_{A}<2 t\right)$ A will charge such a high price that some of the consumers will not buy the application (partial market coverage, Fig. 8(b)].

We will derive the condition that separates the two cases.

Firm A's profits from application sales are $\pi_{A}=p_{A} \hat{x}$ where $\hat{x}$ denotes the location of the consumer furthest away from A who is still willing to buy the application. If only part of the consumers buy the application $\hat{x}$ is the indifferent consumer with $\hat{x}$ satisfying $s_{A}-p_{A}-t \hat{x}=0$ and, therefore, $\hat{x}=\left(s_{A}-p_{A}\right) / t$. If all consumers are willing to buy the platform, i.e. even the consumer at location 1

\footnotetext{
${ }^{38}$ Note that the free Acrobat Reader can only display PDF files, the Standard and Professional versions can also create files.
} 


\begin{tabular}{|c|c|c|c|}
\hline Company & Platform & Own Application & $\begin{array}{l}\text { Competing } \\
\text { Application(s) }\end{array}$ \\
\hline Microsoft & Windows & $\begin{array}{l}\text { Excel } \\
\text { (more generally } \\
\text { MS Office) }\end{array}$ & $\begin{array}{l}\text { Lotus 1-2-3, } \\
\text { OpenOffice Calc }\end{array}$ \\
\hline Adobe & PDF file format & Acrobat Standard & $\begin{array}{l}\text { PDF Writer, } \\
\text { PDF Creator }\end{array}$ \\
\hline IBM & $\operatorname{Linux}^{a}$ & DB2 & Oracle \\
\hline $\begin{array}{l}\text { Google } \\
\text { (froogle.com) }\end{array}$ & $\begin{array}{l}\text { page with } \\
\text { search results }\end{array}$ & $\begin{array}{l}\text { paid ads sold } \\
\text { by Google }\end{array}$ & $\begin{array}{l}\text { links to third- } \\
\text { party web pages } \\
\text { with ads }\end{array}$ \\
\hline Intel Corp. & $\begin{array}{l}\text { Intel compatible } \\
\text { processors }\end{array}$ & Intel processors & AMD processors \\
\hline Nintendo & $\begin{array}{l}\text { Nintendo Entertainment } \\
\text { Systems }\end{array}$ & $\begin{array}{l}57 \% \text { of games } \\
\text { (e.g. Super Mario) }\end{array}$ & $\begin{array}{l}\text { e.g. Dragon Warrior, } \\
\text { Final Fantasy }\end{array}$ \\
\hline \multicolumn{4}{|c|}{ non-software examples } \\
\hline Company & Platform & Own Shop & Competing Shop(s) \\
\hline $\operatorname{Migros}^{b}$ & $\begin{array}{l}\text { Glatt Zentrum } \\
\text { (shopping mall in } \\
\text { Zurich, Switzerland) }\end{array}$ & $\begin{array}{l}\text { Hotelplan } \\
\text { (travel agency) }\end{array}$ & $\begin{array}{l}\text { Kuoni, } \\
\text { Imholz/TUI }\end{array}$ \\
\hline Coop $^{b}$ & $\begin{array}{l}\text { Wankdorf Center } \\
\text { (shopping mall } \\
\text { in Bern, Switzerland) }\end{array}$ & Coop Restaurant & Segafredo \\
\hline
\end{tabular}

${ }^{a}$ IBM is not the owner of Linux. However, they have invested significant amounts (estimated to be more than \$1bn) in Linux and employ over 300 Linux Kernel developers (see http://news.com.com/2100-1001-825723.html and http://en.wikipedia.org/wiki/IBM). IBM could have just as well promoted one of its proprietary operating systems (such as OS/2) which would have given them better chances to exclude competing application vendors. IBM claims to have recouped investments in Linux with increased application and hardware sales (again http://news.com.com/2100-1001-825723.html).

${ }^{b}$ Migros and Coop are major retailers in Switzerland.

Table 2: Examples of platform owners who are also active on one side of the market.

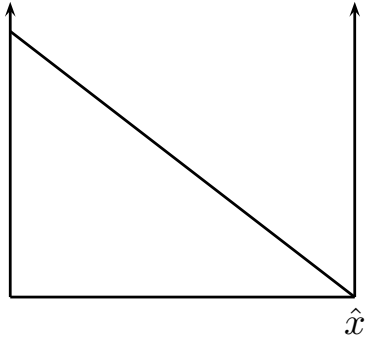

(a) Full Market Coverage

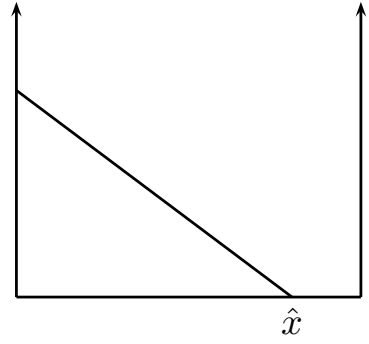

(b) Partial Market Coverage

Figure 8: Cases of monopolistic pricing by A. The vertical axis denotes excess utility $v_{A}-v_{0}$ derived from the usage of application A. 
has a non-negative utility from buying the platform $s_{A}-p_{A}-t \geq 0$ has to be satisfied and $\hat{x}$ is equal to 1 .

Formally we get

$$
\hat{x}= \begin{cases}\left(s_{A}-p_{A}\right) / t & \text { if }\left(s_{A}-p_{A}\right) / t<1, \\ 1 & \text { otherwise. }\end{cases}
$$

Proposition 2 derives the separating condition and shows the equilibrium for the full coverage case.

Proposition 2. (Formalization of Proposition 1) If $s_{A} \geq 2 t$ it is optimal for the monopolist to set $p_{A}^{*}=s_{A}-t$. The consumer at $x=1$ derives a utility 0 from buying the application.

Proof. Substituting $p_{A}=p_{A}^{*}$ and $x=1$ into excess utility $v_{A}-v_{0}=s_{A}-p_{A}-t x$ yields $v_{A}-v_{0}=0$. Therefore, for $p_{A}^{*}=s_{A}-t$ the consumer at location $x=1$ is just indifferent between buying and not buying. Demand is hence 1 and profits are $\pi_{A}^{*}=p_{A}^{*}=s_{A}-t$. It does not pay off to choose a lower price $p_{A}^{l}<p_{A}^{*}$ because demand cannot be larger than 1 and profits are hence $\pi_{A}^{l}=p_{A}^{l}<p_{A}^{*}=\pi_{A}^{*}$. It does not pay off either to choose a higher price $p_{A}^{h}>p_{A}^{*}$. For a higher price demand would be $\hat{x}=\left(s_{A}-p_{A}\right) / t$ which is less than 1 . Profits would be $\pi_{A}^{h}=p_{A}^{h}\left(s_{A}-p_{A}^{h}\right) / t$ and the derivative of the profit function $\partial \pi_{A}^{h} / \partial p_{A}^{h}=s_{A} / 2-p_{A}$. At $p_{A}^{h}=p_{A}^{*}$ (and hence at $\hat{x}=1$ ) the derivative is $t-s_{A} / 2$. For $s_{A} \geq 2 t$ the derivative of the profit function is non-positive at $p_{A}^{h}=p_{A}^{*}$ and decreasing in $p_{A}^{h}$, therefore, $\pi_{A}^{h} \leq \pi_{A}^{*}$ and the firm is not willing to increase its price.

For the case where $s_{A} \leq 2 t$ the monopolist sells only to a part of the consumers.

His profit maximization problem is

$$
\pi_{A}^{*}=\max _{p_{A}} p_{A} \hat{x}=\max _{p_{A}} p_{A} \frac{s_{A}-p_{A}}{t} .
$$

Solving the first order condition for $p_{A}$ yields $p_{A}^{*}=s_{A} / 2$. The location of the marginal consumer and profits are hence $\hat{x}^{*}=s_{A} / 2 t$ and $\pi_{A}^{*}=s_{A}^{2} / 4 t$. Consumer surplus is

$$
\mathrm{EU}=\int_{0}^{\hat{x}^{*}}\left(s_{A}-p_{A}-t x\right) d x=\frac{s_{A}^{*}}{8 t}
$$

\section{Alternative Cases of Competition}

Five cases can be distinguished in a fixed location Hotelling setup: 1. an "inner equilibrium" $\left(s_{A}+s_{B}>\right.$ $3 t$ and $-3 t<s_{A}-s_{B}<3 t$, see Fig. 9(a)], 2. market domination by $\mathrm{A}\left(s_{A}+s_{B}>3 t\right.$ and $s_{A}-s_{B} \geq 3 t$, Fig. 9(b)], 3. market domination by B $\left(s_{A}+s_{B}>3 t\right.$ and $s_{A}-s_{B} \leq-3 t$, Fig. 9(c)], 4 . two local monopolies $\left(s_{A}+s_{B} \leq 2 t\right.$, Fig. 9(d) and 5 . a "limiting case" where prices are too low for a local monopoly, but too high for competition $\left(2 t<s_{A}+s_{B} \leq 3 t\right.$, Fig. 9(e)].

We will derive these conditions and the equilibria arising in the different cases after introducing some notation.

The consumer indifferent between applications $\mathrm{A}$ and $\mathrm{B}$ will be denoted with $\tilde{x}$ satisfying $s_{A}-$ $p_{A}-t \tilde{x}=s_{B}-p_{B}-t(1-\tilde{x})$, the consumer indifferent between buying application $\mathrm{A}$ and not buying any application with $\tilde{x}_{A}$ satisfying $s_{A}-p_{A}-t \tilde{x}_{A}=0$, and the consumer indifferent between $\mathrm{B}$ and not buying with $\tilde{x}_{B}$ satisfying $s_{B}-p_{B}-t\left(1-\tilde{x}_{B}\right)=0$. Solving for $\tilde{x}, \tilde{x}_{A}$, and $\tilde{x}_{B}$ yields

$$
\begin{aligned}
\tilde{x} & =\frac{1}{2}+\frac{1}{2 t}\left(s_{A}-s_{B}+p_{B}-p_{A}\right), \\
\tilde{x}_{A} & =\frac{1}{t}\left(s_{A}-p_{A}\right), \\
\tilde{x}_{B} & =1-\frac{1}{t}\left(s_{B}-p_{B}\right) .
\end{aligned}
$$




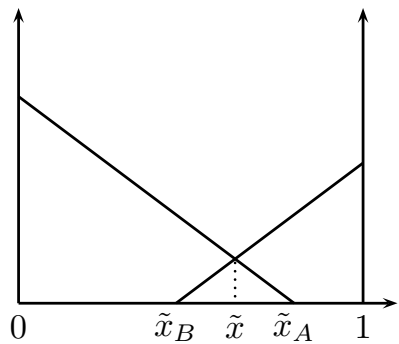

(a) "Inner Equilibrium"

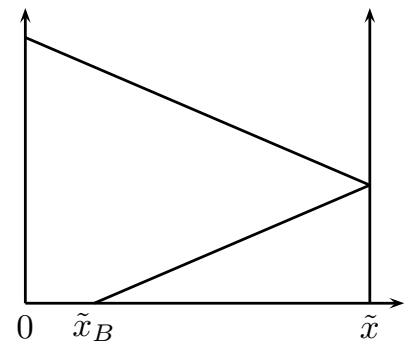

(b) A captures whole market $(\tilde{x}=1)$

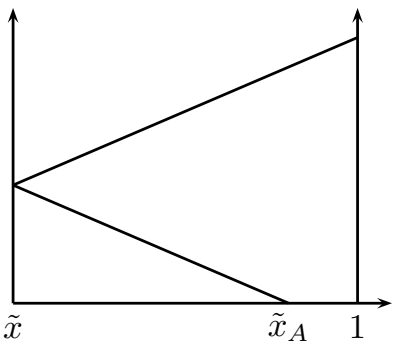

(c) B captures whole market $(\tilde{x}=0)$

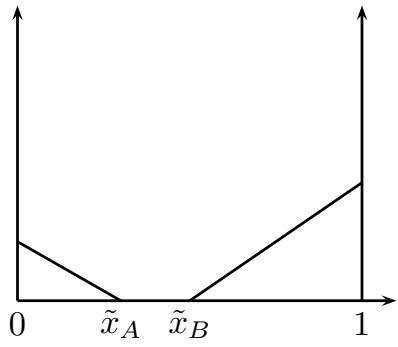

(d) Local Monopolies

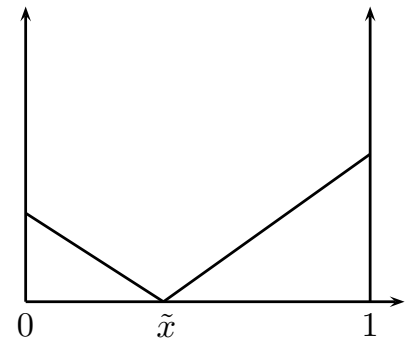

(e) "Limiting Case" $\left(\tilde{x}=\tilde{x}_{A}=\tilde{x}_{B}\right)$

Figure 9: Different cases in a Hotelling setup. The vertical axis on the left denotes the excess utility $v_{A}-v_{0}$ derived from the usage of application $\mathrm{A}$, the vertical axis on the right denotes the excess utility $v_{B}-v_{0}$ from B.

We will call the demand for application A $x_{A}$ and the demand for application $\mathrm{B}\left(1-x_{B}\right)$ where

$$
x_{A}= \begin{cases}0 & \text { if } \tilde{x}<0, \\ \min \left\{\tilde{x}, 1, \tilde{x}_{A}\right\} & \text { else, }\end{cases}
$$

and

$$
x_{B}= \begin{cases}1 & \text { if } \tilde{x}>1, \\ \max \left\{\tilde{x}, 0, \tilde{x}_{B}\right\} & \text { else. }\end{cases}
$$

The five cases can be formally defined as follows:

- "Inner Equilibrium": $\tilde{x}_{B}<\tilde{x}_{A}$ and $0<\tilde{x}<1$

- Domination by A: $\tilde{x} \geq 1$

- Domination by B: $\tilde{x} \leq 0$

- Local Monopolies: $\tilde{x}_{A}<\tilde{x}_{B}$

- "Limiting Case": $\tilde{x}=\tilde{x}_{A}=\tilde{x}_{B}$

The following propositions state the conditions for the cases and the resulting equilibria. As in the main section, we will use $\Delta$ as a shorthand for $s_{A}-s_{B}$. 
Proposition 3. If $s_{A}+s_{B}>3 t$ and $-3 t<\Delta<3 t$ there is an "inner equilibrium" $\left(\tilde{x}_{B}<\tilde{x}_{A}\right.$ and $0<\tilde{x}<1$ ) with equilibrium prices $p_{A}^{*}=t+\Delta / 3$ and $p_{B}^{*}=t-\Delta / 3$.

Proof. Substituting $p_{A}^{*}$ and $p_{B}^{*}$ into $\tilde{x}_{A}$ and $\tilde{x}_{B}$ yields

$$
\tilde{x}_{A}^{*}=\frac{2 s_{A}+s_{B}}{3 t}-1, \quad \tilde{x}_{B}^{*}=-\frac{2 s_{B}+s_{A}}{3 t}+2 .
$$

Substituting this into the condition $\tilde{x}_{B}<\tilde{x}_{A}$ and regrouping yields $3 t<s_{A}+s_{B}$ which is fulfilled by assumption.

Substituting $p_{A}^{*}$ and $p_{B}^{*}$ into $\tilde{x}$ we get $\tilde{x}=1 / 2+\Delta / 6 t$. The condition $0<\tilde{x}<1$ can be rewritten as $-3 t<\Delta<3 t$ which is again fulfilled by assumption.

Because both $\tilde{x}_{B}<\tilde{x}_{A}$ (and thus $\tilde{x}_{B}<\tilde{x}<\tilde{x}_{A}$ ) and $0<\tilde{x}<1$ hold we can write the demand functions specified in (C.4) and (C.5) as $x_{A}=\tilde{x}$ and $1-x_{B}=1-\tilde{x}$. The Nash equilibrium is hence

$$
\begin{aligned}
& p_{A}^{*}=\arg \max _{p_{A}} p_{A} \tilde{x}\left(p_{A}, p_{B}^{*}\right) \\
& p_{B}^{*}=\arg \max _{p_{B}} p_{B}\left(1-\tilde{x}\left(p_{A}^{*}, p_{B}\right)\right) .
\end{aligned}
$$

Solving the first order conditions of the two maximization problems for $p_{A}$ and $p_{B}$ yields $p_{A}^{*}=t+\Delta / 3$ and $p_{B}^{*}=t-\Delta / 3$.

Proposition 4. If $s_{A}+s_{B}>3 t$ and $\Delta \geq 3 t A$ will capture the whole market ( $\tilde{x} \geq 1$ ) and equilibrium prices are $p_{A}^{*}=s_{A}-s_{B}-t$ and $p_{B}^{*}=0$.

Proof. Substituting $p_{A}^{*}$ and $p_{B}^{*}$ into $\tilde{x}$ yields

$$
\tilde{x}^{*}=\frac{1}{2}+\frac{1}{2 t}\left(s_{A}-s_{B}+p_{B}^{*}-p_{A}^{*}\right)=1 .
$$

$\mathrm{B}$ has no incentive to deviate from $p_{B}^{*}=0$ : with a negative price her profits would be non-positive, with a higher price her demand would remain zero.

A has no incentive to deviate either. With a lower price his demand would still be 1, therefore, his profits would decrease.

The reason why he would not set a higher price is the following. At $p_{A}=p_{A}^{*}$ the derivative of the profit function $\pi_{A}=p_{A} \tilde{x}$ is

$$
\left.\frac{\partial \pi_{A}}{\partial p_{A}}\right|_{p_{A}=p_{A}^{*}}=\frac{3 t-\left(s_{A}-s_{B}\right)}{2 t} .
$$

The derivative is non-positive at $p_{A}^{*}$ for $s_{A}-s_{B} \geq 3 t$ and linearly decreasing in $p_{A}$. Therefore, $\mathrm{A}$ has no interest in increasing the price.

Proposition 5. If $s_{A}+s_{B}>3 t$ and $\Delta \leq-3 t B$ will capture the whole market ( $\tilde{x} \leq 0$ ) and equilibrium prices are $p_{A}^{*}=0$ and $p_{B}^{*}=s_{B}-s_{A}-t$.

Proof. By analogy to Proposition 4 .

Proposition 6. If $s_{A}+s_{B}<2 t$ there are local monopolies $\left(\tilde{x}_{A}<\tilde{x}_{B}\right)$ and equilibrium prices are $p_{A}^{*}=s_{A} / 2$ and $p_{B}^{*}=s_{B} / 2$.

Proof. Substituting $p_{A}^{*}$ and $p_{B}^{*}$ into $\tilde{x}_{A}$ and $\tilde{x}_{B}$ yields $\tilde{x}_{A}=s_{A} / 2 t$ and $\tilde{x}_{B}=1-s_{B} / 2 t$. Substituting this into $\tilde{x}_{A}<\tilde{x}_{B}$ gives $s_{A} / 2 t<1-s_{B} / 2 t$ which is equivalent to $s_{A}+s_{B}<2 t$ and hence fulfilled by assumption. 
$\tilde{x}$ has to be between $\tilde{x}_{A}$ and $\tilde{x}_{B}$, therefore, we can write demand as $x_{A}=\tilde{x}_{A}$ and $1-x_{B}=$ $1-\tilde{x}_{B}$. The two local monopolists do not compete with each other, hence the two firms choose profit maximizing prices independently and we get

$$
\begin{aligned}
& p_{A}^{*}=\arg \max _{p_{A}} p_{A} \tilde{x}_{A}\left(p_{A}\right)=\frac{s_{A}}{2}, \\
& p_{B}^{*}=\arg \max _{p_{B}} p_{B}\left(1-\tilde{x}_{B}\left(p_{B}\right)\right)=\frac{s_{B}}{2} .
\end{aligned}
$$

by solving the first-order conditions.

When neither of the aforementioned cases occurs $\left(2 t \leq s_{A}+s_{B} \leq 3 t\right)$, we have the "limiting case" with $\tilde{x}=\tilde{x}_{A}=\tilde{x}_{B}$.

\section{Monopolist with Two Applications}

One can consider the case where the platform owner owns both application A and application B, either because he has developed application $B$ himself or because he acquired firm B. Let $f_{A B}$ be firm A's fixed costs of developing application $\mathrm{B} 39$ or the price he has to pay to acquire the competitor.

Similarly to Section 3 we assume that $s_{A}+s_{B}>2 t 40$ (In the case $s_{A}+s_{B}<2 t$ the two-application monopolist would not cover the whole market and we have the same case as two independent local monopolies as described in Appendix (B)

At stage 2 the monopolist sets prices such that consumer $\tilde{x}$ who is indifferent between buying an application and not buying, i.e. $v_{A}(\tilde{x})=v_{B}(\tilde{x})=v_{0}$ or

$$
s_{A}-p_{A}-t \tilde{x}=s_{B}-p_{B}-t(1-\tilde{x})=0 .
$$

We can solve this double equation for both $\tilde{x}$ and $p_{B}$. The profit maximization problem becomes $\max _{p_{A}, p_{B}}\left\{p_{A} \tilde{x}+p_{B}(1-\tilde{x})\right\}$ or

$$
\max _{p_{A}} p_{A} \frac{s_{A}-p_{A}}{t}+\left(s_{A}+s_{B}-p_{A}-t\right)\left(1-\frac{s_{A}-p_{A}}{t}\right) .
$$

Solving the first order conditions gives us

$$
\begin{aligned}
p_{A}^{*} & =\frac{3}{4} s_{A}+\frac{1}{4} s_{B}-\frac{t}{2}, \\
p_{A}^{*} & =\frac{1}{4} s_{A}+\frac{3}{4} s_{B}-\frac{t}{2}, \\
\tilde{x}^{*} & =\frac{1}{2}+\frac{\Delta}{4 t} .
\end{aligned}
$$

The condition $0<\tilde{x}^{*}<1$ is fulfilled if $-2 t<\Delta<2 t$ with $\Delta \equiv s_{A}-s_{B}$ as previously. For $\Delta$ outside of this range the monopolist sells only one of his applications. For stage 2 profits and expected consumer surplus we get

$$
\begin{aligned}
\pi_{A}^{*}+\pi_{B}^{*} & =\frac{s_{A}+s_{B}-t}{2}+\frac{\Delta}{8 t}, \\
\mathrm{EU} & =\frac{t}{4}+\frac{\Delta^{2}}{16 t} .
\end{aligned}
$$

Stage 1 profits are the same as in Eq. (3.11) except that now we have $\pi_{A}^{*}+\pi_{B}^{*}$ instead of $\pi_{A}^{*}$

$$
\Pi^{* \mathrm{two}}=\frac{\alpha}{4}\left(s+\mathrm{EU}+\pi_{A}^{*}+\pi_{B}^{*}\right)^{2}=\frac{\alpha}{4}\left[s+\frac{t}{4}+\frac{3 \Delta^{2}}{16 t}+\frac{s_{A}+s_{B}}{2}\right]^{2} .
$$

\footnotetext{
${ }^{39}$ We assume that if firm A develops an application located at $x=1$ on the Hotelling line, firm B does not enter the market, because this would lead to Bertrand competition and fixed costs could not be covered.

${ }^{40}$ Note that we have $2 t$ instead of $3 t$ here. This weaker assumption is sufficient, because the "inner equilibrium" and "limiting" cases described in Appendix [ are identical in this setup, as it will be shown later.
} 


\section{D.1 Comparison with Single Application Monopolist}

Now we can compare the single application monopolist's profits with the profits of the two application monopolist. Developing a second application (or acquiring the competitor) incurs fixed costs $f_{A B}$, therefore we have to compare $\Pi^{* \text { two }}-f_{A B}$ with $\Pi^{* M}$ from Eq. (3.11). Developing a second application pays off for the monopolist if $\Pi^{* t w o}-f_{A B}>\Pi^{* M}$. It can be (trivially) seen that for $f_{A B}$ sufficiently large, it does not pay off to develop a second application. It can further be shown that if development costs for the second application are zero, it always pays off to develop it (i.e. $\Pi^{* \text { two }}>\Pi^{* M}$, see Proposition [7).

Proposition 7. $\Pi^{* t w o}>\Pi^{* M}$

Proof. Substituting (D.1) and (3.11) into $\Pi^{* \text { two }}>\Pi^{* M}$ and regrouping yields $3 \Delta^{2}-8 t \Delta+20 t^{2}>0$. Because the coefficient of $\Delta^{2}$ is positive and the polynomial in $\Delta$ has no real roots, the equation is always fulfilled.

\section{D.2 Comparison with Competition}

Having a competitor compared to developing both products oneself pays off if $\Pi^{* \text { two }}-f_{A B}>\Pi^{* C}$ with $\Pi^{* C}$ taken from Eq. (4.12). Again, for $f_{A B}$ sufficiently large, it does not pay off to develop the second application. And again, it can be shown that for $f_{A B}=0$ it pays off to develop a second application oneself instead of letting the competitor develop it (see Proposition 8 ).

Proposition 8. $\Pi^{* t w o}>\Pi^{* C}$

Proof. Substituting Eq. (D.1) and (4.12) into $\Pi^{* \text { two }}>\Pi^{* C}$ and regrouping yields $5 \Delta^{2}-16 t \Delta+48 t^{2}>$ 0 . Again, this polynomial in $\Delta$ has no real roots and therefore the left hand side is always positive.

\section{E Model with Different Distribution of Consumers}

Alternatively to the results subsection 6.2 we can consider a different distribution of consumer preferences in order to get a purely analytical solution: consumers are homogeneous with respect to their preferences for the platform and all have the parameter value $y_{1}$ as depicted in Fig. 10.

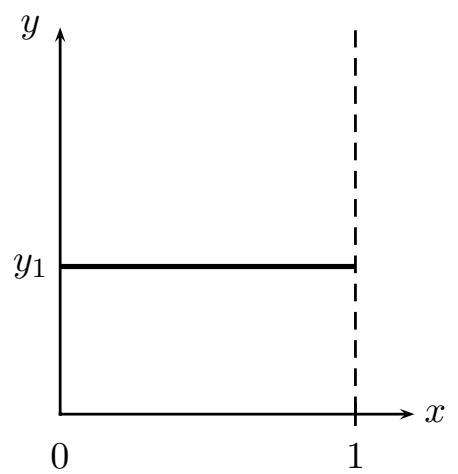

Figure 10: Consumers with homogeneous preferences $y=y_{1}$ over the platform

We can describe the density of consumers with the Dirac delta function $\delta(\cdot)$ used in physics:

$$
\rho(x, y)= \begin{cases}\delta\left(y-y_{1}\right) & \text { for } 0 \leq x \leq 1 \\ 0 & \text { otherwise }\end{cases}
$$


The number of consumers between 0 and $\tilde{y}$ is thus

$$
N=\int_{0}^{\tilde{y}} \int_{0}^{1} \rho(x, y) d x d y= \begin{cases}1 & \text { if } \tilde{y} \geq y_{1}, \\ 0 & \text { otherwise }\end{cases}
$$

i.e. either all consumers buy the platform or none. We will first look at the monopoly case in this setup and then at the competition case. We will show that it is possible that a monopolist cannot sell his platform even if he can commit to the application price at stage 1 . Then we shown that in such a situation competition can be a remedy.

\section{E.1 Monopoly}

As in Section 3 we assume full market coverage, i.e. the monopolist sets the application price such that consumers with all values of $x$ are willing to buy the application. However, contrary to the previous sections, the outermost consumer $(x=1)$ is not necessarily set indifferent between buying and not buying (see Fig. 111), because the monopolist may be willing to commit to a lower $p_{A}$ at stage 1 to convince consumers to buy the platform.

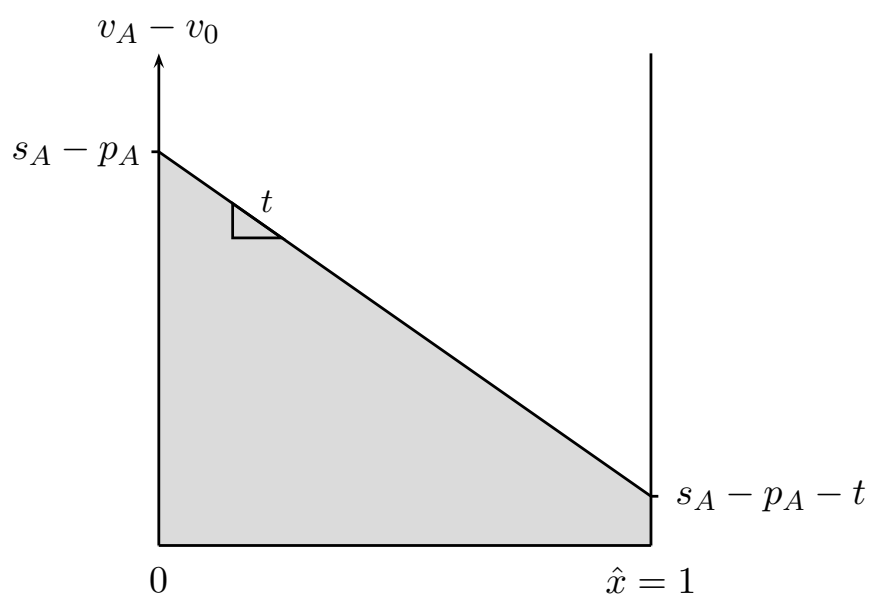

Figure 11: Full coverage with price commitment at stage 1. The shaded area below the curve denotes consumer surplus.

For stage 2 profits and expected consumer surplus we get $\pi_{A}=p_{A}$ and $\mathrm{EU}=s_{A}-p_{A}-t / 2$.

The condition for full market coverage at stage 1 is

$$
s_{A}-p_{A} \geq t .
$$

At stage 1, consumers are willing to buy the platform if their $y$ is not above

$$
\tilde{y}=s+\mathrm{EU}=s+s_{A}-p_{A}-\frac{t}{2} .
$$

Because all consumers have $y=y_{1}$, the monopolist has to commit to a price $p_{A}$ at stage 1 such that

$$
\tilde{y} \geq y_{1}
$$

to ensure that consumers are willing to buy his platform.

The profit maximization problem of the monopolist consists of setting $p_{A}$ as high as possible such that conditions (E.1) and (E.2) are still satisfied. We take the case where condition (E.2) is stronger 
than condition (E.1) and the monopolist sets $p_{A}$ such that $(\underline{E .2})$ is just binding:

$$
y_{1}=s+s_{A}-p_{A}-\frac{t}{2} .
$$

For the equilibrium application price we get

$$
p_{A}^{*}=s+s_{A}-\frac{t}{2}-y_{1}
$$

and for overall profits

$$
\Pi^{*}=\pi_{A}^{*} N^{*}=s+s_{A}-\frac{t}{2}-y_{1},
$$

because $\pi_{A}^{*}=p_{A}^{*}$ and $N^{*}=1$.

Now let us consider the case where

$$
y_{1}>s+s_{A}-\frac{t}{2}
$$

In this case the firm would have to set a negative price $p_{A}$ for the application to convince consumers to buy his platform. Hence, in this case it is not possible for the monopolist to get positive profits.

\section{E.2 Competition}

If $\mathrm{B}$ enters the market, both firms commit to application prices at stage 1. They face the same problem as at stage 2 in the previous sections with the additional constraint that consumers should be willing to buy the platform:

$$
\tilde{y} \geq y_{1}
$$

where $\tilde{y}=s+\mathrm{EU}$ is the maximal distance at which consumers are still willing to buy the platform.

We consider the case where $(\underline{E .4}$ is non-binding. In this case we can use the results obtained in subsection 4.1 the only difference is that prices are set at stage 1 and not at stage 2. Equilibrium stage 2 profits and expected consumer surplus are given in Eqs. (4.5), (4.6), and (4.8).

Firm A's profits are $\Pi^{*}=\pi_{A}^{*} N^{*}=\pi_{A}^{*}$ because $N^{*}=1$.

\section{E.3 Comparison of Profits}

In the case where the monopolist cannot achieve positive profits, but with competition profits are strictly positive, firm A is (trivially) better off with competition. This case occurs for parameter values which satisfy both conditions (E.3) and (E.4). Proposition 9 states when both conditions can be satisfied simultaneously.

Proposition 9. For $\Delta \in(-3 t,(9-6 \sqrt{3}) t)$ conditions (E.3) and (E.4) can both be satisfied at once if neither firm dominates the market.

Proof. Substituting (4.8) into (E.4) gives

$$
y_{1} \leq \frac{\Delta^{2}}{36 t}+\frac{s_{A}}{2}+\frac{s_{B}}{2}-\frac{5}{4} t
$$

Combining this with (E.3) yields

$$
s+s_{A}-\frac{t}{2}<y_{1} \leq \frac{\Delta^{2}}{36 t}+\frac{s_{A}}{2}+\frac{s_{B}}{2}-\frac{5}{4} t .
$$

The range of $y_{1}$ which allows for both conditions to be satisfied is non-empty if the lower bound of $y_{1}$ given in the previous equation is less than its upper bound. This is satisfied if $\Delta^{2}-18 t \Delta-27 t^{2}>0$. The roots of this polynomial in $\Delta$ are

$$
\Delta_{1,2}=(9 \pm 6 \sqrt{3}) t \approx\{-1.4 t, 19.4 t\} .
$$


The polynomial is positive for values of $\Delta$ not between the roots. Combining this with the assumption that neither firm dominates the market $(-3 t<\Delta<3 t$, see Eq. (4.2) ) we get

$$
-3 t<\Delta<(9-6 \sqrt{3}) t .
$$

\section{References}

Armstrong, M. (2005): "Competition in Two-Sided Markets," Industrial organization, Economics Working Paper Archive EconWPA.

BegGs, A. W. (1994): "Mergers and Malls," Journal of Industrial Economics, 42(4), 419428.

Besen, S. M., and J. Farrell (1994): "Choosing How to Compete: Strategies and Tactics in Standardization," Journal of Economic Perspectives, 8, 117-310.

Caillaud, B., and B. Jullien (2003): "Chicken \& Egg: Competition among Intermediation Service Providers," RAND Journal of Economics, 34(2), 309-28.

ECONOMIDES, N. (1996): "Network externalities, complementarities, and invitations to enter," European Journal of Political Economy, 12(2), 211-233.

_ (1997): "Raising Rivals' Costs in Complementary Goods Markets: LECs Entering into Long Distance and Microsoft Bundling Internet Explorer," Discussion Paper EC-98-03, Stern School of Business.

Economides, N., And B. Viard (2004): "Pricing of Complementary Goods and Network Effects," Industrial organization, Economics Working Paper Archive EconWPA.

Evans, D. S., A. Hagiu, and R. Schmalensee (2004): "A Survey of the Economic Role of Software Platforms in Computer-Based Industries," Cesifo working paper series, CESifo $\mathrm{GmbH}$.

Farrell, J., And N. T. Gallini (1988): "Second-Sourcing as a Commitment: Monopoly Incentives to Attract Competition," The Quarterly Journal of Economics, 103(4), 673-94.

Hagiu, A. (2004): "Platforms, Pricing, Commitment And Variety In Two-Sided Markets," Ph.D. thesis, Princeton University.

Loertscher, S., And Y. Schneider (2005): "Switching Costs, Firm Size, and Market Structure," Diskussionsschriften, Universitat Bern, Volkswirtschaftliches Institut.

Nocke, V., M. Peitz, and K. O. Stahl (2004): "Platform Ownership," Cepr discussion papers.

Parker, G. G., and M. W. Van Alstyne (2000): "Information Complements, Substitutes, and Strategic Product Design," William Davidson Institute Working Papers Series 299.

Rochet, J.-C., And J. Tirole (2003): "Platform Competition in Two-Sided Markets," Journal of the European Economic Association, 1(4), 990-1029. 
Varian, H. R., And C. Shapiro (1998): Information Rules: A Strategic Guide to the Network Economy. Harvard Business School Press. 